\title{
Growth, Defects and Doping of 3C-SiC on Hexagonal Polytypes
}

\author{
R. Yakimova ${ }^{\mathrm{a}}$, I. G. Ivanov ${ }^{\mathrm{a}}$, L. Vines ${ }^{\mathrm{b}}$, M. K. Linnarsson ${ }^{\mathrm{c}}$, A. Gällström ${ }^{\mathrm{a}}$, F.Giannazzo ${ }^{\mathrm{d}}$, \\ F. Roccaforte ${ }^{\mathrm{d}}$, P. Wellmann ${ }^{\mathrm{e}}$, M. Syväjärvi ${ }^{\mathrm{a}}$, V. Jokubavicius ${ }^{\mathrm{a}}$ \\ ${ }^{a}$ Department of Physics, Chemistry and Biology, Linköping University, SE-58183, \\ Linköping, Sweden \\ ${ }^{\mathrm{b}}$ Physics Department/Center for Materials Science and Nanotechnology, University of \\ Oslo, N-0316 Oslo, Norway \\ ${ }^{c}$ Department of Applied Physics, KTH Royal Institute of Technology, SE-16440 Kista, \\ Sweden \\ ${ }^{\mathrm{d}}$ CNR-IMM, Strada VIII n. 5, Zona Industriale, 95121, Catania, Italy \\ ${ }^{\mathrm{e}}$ Materials Department 6 (i-meet), Crystal Growth Lab, University of Erlangen, \\ D-91058 Erlangen, Germany
}

Technologies for the growth of 3C-SiC with crystalline quality and crystal size similar to hexagonal counterparts $(6 \mathrm{H}-$ or $4 \mathrm{H}-\mathrm{SiC})$ are still at the laboratory stage. There are several challenges in the control of polytype stability and formation of structural defects which have to be eliminated to reveal the full potential of this material. Nevertheless, 3C-SiC has been explored for various energy, environment and biomedical applications which significantly benefit from the intrinsic semiconductor properties of this material. The future of $3 \mathrm{C}-\mathrm{SiC}$ and its applications depends on the advances which will be made in improving crystalline quality, enlarging crystal size and controlling doping levels which have not been entirely explored due to the lack of high quality $3 \mathrm{C}-\mathrm{SiC}$ substrates. This paper reviews recent progress in growth and doping of thick $3 \mathrm{C}-\mathrm{SiC}$ layers on hexagonal $\mathrm{SiC}$ substrates using sublimation epitaxy. It covers the growth process on off-axis substrates and defects occurrence, as well as the issue of obtaining high resistivity material.

\section{Introduction}

In recent years cubic silicon carbide (3C-SiC) has been regaining its importance among other $\mathrm{SiC}$ polytypes in development of various semiconductor device applications. In addition to active devices it can be used as a substrate for growth of high quality nitrides or epitaxial graphene layers (1-3). The quality of the latter greatly benefits from the absence of the energy driven step bunching which occurs in the hexagonal polytypes upon heating above a certain temperature due to the anisotropy of the crystal structure. The high electron mobility $\left(\sim 1000 \mathrm{~cm}^{2} \mathrm{~V}^{-1} \mathrm{~s}^{-1}\right)$ and lower bandgap $(\sim 2.3 \mathrm{eV})$ of $3 \mathrm{C}-\mathrm{SiC}$, compared to hexagonal $\mathrm{SiC}$ polytypes, enabled researchers to demonstrate the best channel mobility values $\left(>200 \mathrm{~cm}^{2} \mathrm{~V}^{-1} \mathrm{~s}^{-1}\right)$ among the SiC-based MOSFETs devices (4). There are also uprising innovative applications like intermediate band solar cells, photo electrochemical devices for water splitting, quantum communication or biomedical applications which significantly benefit from the intrinsic $3 \mathrm{C}-\mathrm{SiC}$ properties (5-10). 
Due to the lack of bulk 3C-SiC crystals, hetero-epitaxial growth on $\mathrm{Si}$ or hexagonal $\mathrm{SiC}$ substrates is the way used today to obtain $3 \mathrm{C}-\mathrm{SiC}$ material with a size suitable for device fabrication. However, such $3 \mathrm{C}$-SiC does not demonstrate the full potential of its intrinsic semiconductor properties due to a high density of defects, e.g. stacking faults, which are formed at the $3 \mathrm{C}-\mathrm{SiC} /$ substrate interface. This problem is more pronounced in 3C-SiC grown on $\mathrm{Si}$ due to the large mismatch in lattice parameters and thermal expansion coefficients, despite that the majority of functioning devices, varying from MOSFETs to MEMS, have been demonstrated using such material (11-14). Therefore, it can be expected that mastering the growth and doping of $3 \mathrm{C}-\mathrm{SiC}$ on hexagonal $\mathrm{SiC}$ substrates, especially providing high resistivity $3 \mathrm{C}-\mathrm{SiC}$ material, would allow validating semiconductor devices of improved performance.

In this paper, we present an overview on the growth and doping of thick $3 \mathrm{C}$-SiC layers grown on hexagonal $\mathrm{SiC}$ substrates using sublimation epitaxy performed at Linköping University. Such layers can be used as substrates for homoepitaxial structures or/and as seeds for bulk growth of $3 \mathrm{C}-\mathrm{SiC}$ material.

\section{$\underline{\text { Sublimation epitaxy }}$}

Originally, the sublimation epitaxy was developed for the growth of thick homoepitaxial $4 \mathrm{H}$ - or $6 \mathrm{H}-\mathrm{SiC}$ layers (15). But then, it has been demonstrated in several studies that it can be adopted for the growth of 3C-SiC material (16-19). The growth setup consists of inductively heated graphite crucible inserted in graphite insulation. Inside the crucible the materials are stacked in a sandwich-like arrangement as shown in Fig. 1. Tantalum (Ta) foil is placed at the bottom, the source material, in a form of a CVD or PVT grown polycrystalline $\mathrm{SiC}$ plate, on top of it followed by the graphite spacer, the substrate and the graphite plate. The driving force for the growth is the temperature difference between the source, which is placed in a higher temperature zone, and the substrate. The distance between the source and the substrate is usually adjusted between 1 to $4 \mathrm{~mm}$. The vapor phase stoichiometry above the $\mathrm{SiC}$ source or substrate is thermodynamically fixed and depends on temperature. Since Ta acts as a carbon getter at elevated



Figure 1. Sublimation epitaxial growth arrangement in cross section. temperatures, it reacts with carbon bearing species and forms $\mathrm{TaC}(20)$. In this way, the vapor phase composition can be enriched with $\mathrm{Si}$ species what is believed to be beneficial for the $3 \mathrm{C}-\mathrm{SiC}$ polytype stability $(21,22)$. Moreover, the growth of $3 \mathrm{C}-\mathrm{SiC}$ is performed at temperatures below $2000^{\circ} \mathrm{C}$ which also provides more silicon enriched growth environment due to the higher partial pressure of silicon compared to other species sublimating from $\mathrm{SiC}$ (23). In addition, the growth ambient is typically "vacuum" (E-5 mbar) which allows, in the frame of the growth geometry, kinetically limited mass transport of the vapor species leading to high $3 \mathrm{C}-\mathrm{SiC}$ growth rates reaching $1 \mathrm{~mm} /$ hour in our growth setup. 
Most of the growth studies of $3 \mathrm{C}-\mathrm{SiC}$ on $\mathrm{SiC}$ by sublimation techniques were made using nominally on-axis hexagonal $\mathrm{SiC}$ substrates $(18,24-27)$. Nominally on-axis surfaces contain large terraces on which the probability to exceed the supersaturation threshold needed to induce $2 \mathrm{D}$ nucleation of $3 \mathrm{C}-\mathrm{SiC}$ on a terrace is much higher compared to that on off-oriented surfaces (28). However, this approach has not succeeded in reproducible growth of high quality $3 \mathrm{C}-\mathrm{SiC}$ material. One of the main reasons is the mismatch of symmetries between the $\mathrm{SiC}(0001)$ and $3 \mathrm{C}-\mathrm{SiC}$ (111) which leads to formation of high density of rotated domains that cannot merge upon enlargement. Instead, structural defects, called double positioning boundaries (DPBs) are formed at the borders of such domains (Fig. 2a). It has been demonstrated that DPBs degrade Schottky contacts characteristics and electrical transport in the material $(29,30)$. Moreover, DPBs hamper the growth of bulk $3 \mathrm{C}-\mathrm{SiC}$ since they enlarge with the thickness and severely deteriorate the quality of the crystal.

In contrast to on-axis substrates, the off-orientated substrates have been a common choice for the growth of homoepitaxial hexagonal SiC layers or bulk crystals. The offoriented surfaces contain high density of steps which ensure efficient incorporation of adatoms at the kink sites leading to the reproduction of the substrate polytype. Generally, this has been considered as an obstacle towards stable 3C-SiC growth. However, under certain conditions, off-oriented $\mathrm{SiC}$ substrates can be used to grow $3 \mathrm{C}-\mathrm{SiC}$ with well controlled initial nucleation using sublimation epitaxy. The growth of 3C-SiC layers on off-oriented $\mathrm{SiC}$ substrates pass through three interconnected stages which include formation of a large terrace with an on-axis area at the edge of the sample, preferential nucleation of $3 \mathrm{C}-\mathrm{SiC}$ domains on the large terrace, and their lateral enlargement along the step-flow direction. Such growth mechanism leads to a significantly lower density of DPBs formed in the 3C-SiC layer (17). An obvious difference in DPBs density can be seen in Fig. 2a-b where 3C-SiC grown on off-oriented substrate contains larger domains and less DPBs compared to the on-axis sample.
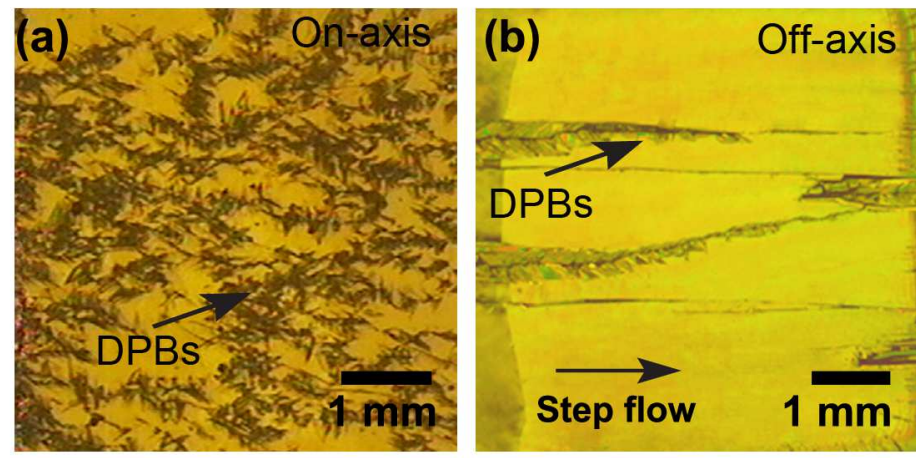

Figure 2. Optical micrographs of 3C-SiC grown: a) on nominally on-axis $4 \mathrm{H}-\mathrm{SiC}(0001)$ substrate, b) on 4 degrees off-oriented $4 \mathrm{H}-\mathrm{SiC}(0001)$.

In order to obtain a $3 \mathrm{C}-\mathrm{SiC}$ layer with as low as possible number of domains, ultimately, a single domain, two conditions must be fulfilled:

i) formation of a minimum number of $3 \mathrm{C}-\mathrm{SiC}$ domains on the large (side) terrace during the initial growth,

ii) the area on which $3 \mathrm{C}-\mathrm{SiC}$ domains form should be minimized to facilitate singledomain formation. 
The first condition can be met by using a two-step process which is based on the initial 3C-SiC formation at lower temperature $\left(\sim 1800^{\circ} \mathrm{C}\right)$ followed by the growth at higher temperatures as shown in Fig. 3a. Such process gives a trade-off between the growth rate and the number of defects in the $3 \mathrm{C}-\mathrm{SiC}$ layers. The second condition can be met by changing the spacer opening geometry. As shown in Fig. 3b, in addition to the original squared spacer opening $\left(7 \times 7 \mathrm{~mm}^{2}\right)$ we explored the same square opening as the original one, but rotated by 45 degrees with respect to the [11-20] direction, as well as a circular one with a diameter of $7 \mathrm{~mm}$. In both cases the area of the large terrace is reduced compared to the original spacer opening. By combining the two-step process with 45 degree rotated or circular spacer opening a single domain $3 \mathrm{C}$-SiC formation on the large terrace was obtained (16).

(a)

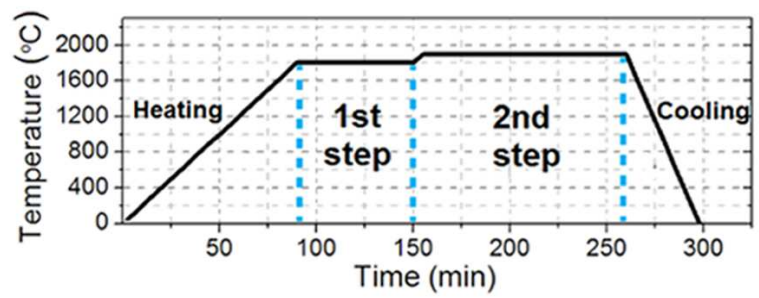

(b)



Figure 3. a) Schematics of two step process, b) spacers with diffrent opening shapes.

The enlargement of such domain along the step flow direction resulted in DPB-free $3 \mathrm{C}-\mathrm{SiC}$ layers shown in Fig. 4a. Considering that sublimation growth of bulk $\mathrm{SiC}$ crystals is commonly performed in cylindrical graphite crucibles, a circular $3 \mathrm{C}$-SiC seeding layer would be most compatible with the geometrical constrains of the crucible. A freestanding 3C-SiC layer obtained after polishing away the substrate is shown in Fig. 4b. Based on HRXRD measurements we can state that the 3C-SiC possesses the same off-cut angle as the hexagonal substrate. Also, as shown in Fig. 4c the surface of 3C-SiC contains high density of steps with height mostly distributed between $0.25-0.5 \mathrm{~nm}$. Such surface structure is very advantageous for homopeitaxial growth. The full width at half maximum (FWHM) values of the $\omega$ rocking curves of such layers vary from 25 to 50 arc seconds which indicates a high crystalline quality of the material.
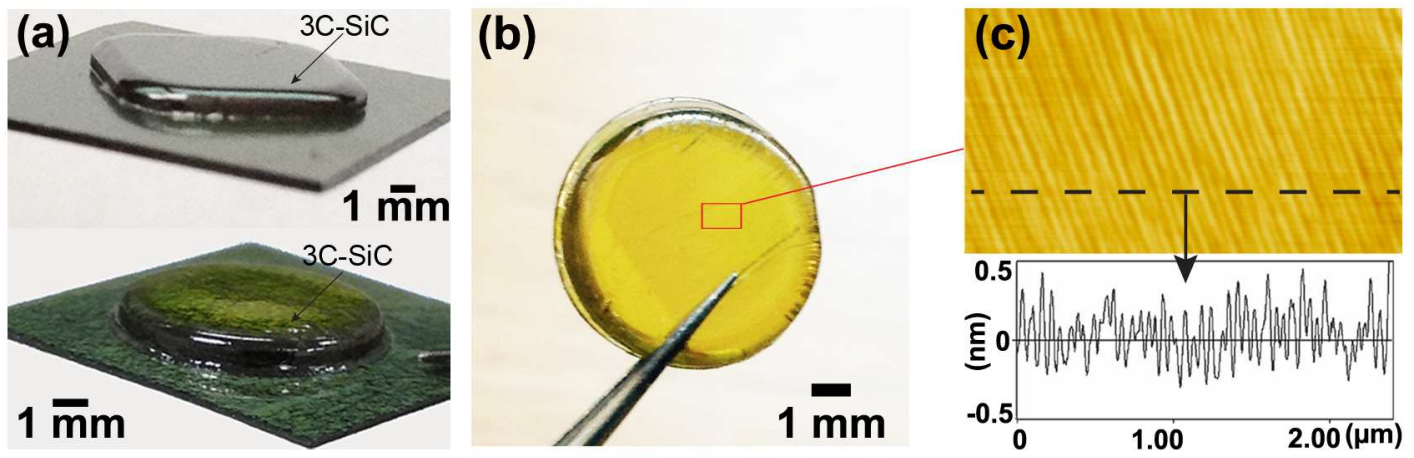

Figure 4. Optical micrograph of 3C-SiC: a) grown using using 45 degrees rotated (top) and circular spacer openings (bottom), b) free-standing layer, c) AFM image of 3C-SiC surface.

Also, 3C-SiC layers can be grown with the thickness of more than $1 \mathrm{~mm}$. Considering thermal stresses which are created in the seed attached to the lid or graphite plate during the PVT bulk growth, such thickness of $3 \mathrm{C}-\mathrm{SiC}$ seeds is highly preferable for the growth of low defect density crystals. 
Until now not so much is published on intentionally doped 3C-SiC by sublimation epitaxy. If the process is based on a pure physical vapor transport (PVT), active gases are not used and doping may be done by using a doped source material which is a polycrystalline $\mathrm{SiC}$ plate prepared by the modified PVT technique (31). In conventional sublimation epitaxy, without having special precautions, grown material may be unintentionally doped with $\mathrm{B}, \mathrm{N}$, and $\mathrm{Al}$ which are typical impurities in the source material on a level E16 $\mathrm{cm}^{-3}-\mathrm{E} 17 \mathrm{~cm}^{-3}$. We have shown earlier (32) that after special purification of the $\mathrm{SiC}$ source synthesized by CVD the level of the major background impurities in $4 \mathrm{H}-\mathrm{SiC}$ grown by sublimation epitaxy can be brought down to low $\mathrm{E} 15 \mathrm{~cm}^{-3}$ but the material was strongly compensated. In the current study, we aimed at understanding the co-doping at higher impurity concentrations which take place in the source synthesized by the modified PVT technique. Vanadium was of a special interest because of the potential to obtain high resistivity $3 \mathrm{C}$-SiC epitaxial layers. Dopants like $\mathrm{B}$, $\mathrm{N}, \mathrm{Al}$, Ti and $\mathrm{V}$ can be introduced into the homoepitaxial 3C-SiC layer by co-doping from the source material. We used source that was grown on isostatically pressed graphite plate yielding formation of $4 \mathrm{H}-, 6 \mathrm{H}$ - and $15 \mathrm{R}-\mathrm{SiC}$ grains while the formation of $3 \mathrm{C}-\mathrm{SiC}$ is suppressed due to the high process temperature (33). To explore co-doping of 3C-SiC homopeitaxial layers we used two different polycrystalline SiC sources (Fig. 5) with different concentrations of impurities which were determined by SIMS. The first one (Fig. 5a) was intentionally doped with $\mathrm{B}\left(\sim \mathrm{E} 18 \mathrm{~cm}^{-3}\right)$ and $\mathrm{N}\left(\sim \mathrm{E} 18 \mathrm{~cm}^{-3}\right)$ with a background doping of $\mathrm{Al}\left(\sim \mathrm{E} 17 \mathrm{~cm}^{-3}\right)$. The second one (Fig. $\left.5 \mathrm{~b}\right)$ was intentionally doped with $\mathrm{V}\left(\sim 5 \times \mathrm{E} 17 \mathrm{~cm}^{-3}\right)$ and contained background doping of $\mathrm{B}\left(\sim 2 \times \mathrm{E} 17 \mathrm{~cm}^{-3}\right), \mathrm{N}$ (below detection limit of $\left.5 \times \mathrm{E} 17 \mathrm{~cm}^{-3}\right), \mathrm{Al}\left(\sim \mathrm{E} 16 \mathrm{~cm}^{-3}\right)$, and Ti $\left(\sim \mathrm{E} 16 \mathrm{~cm}^{-3}\right)$. The co-doped $3 \mathrm{C}$ $\mathrm{SiC}$ epilayers with thicknesses varying from 50 to $600 \mu \mathrm{m}$ were grown at $1800^{\circ} \mathrm{C}$ and a base pressure of $\mathrm{E}-5$ mbar on unintentionally doped $3 \mathrm{C}-\mathrm{SiC}$ substrates containing residual nitrogen concentration in the range of E16 $\mathrm{cm}^{-3}$ which was estimated using FWHM of TA-phonon replica as proposed by J. Camassel et al (34). After growth the homoepitaxial co-doped 3C-SiC layers and the source material were analyzed using SIMS. It was observed that $\mathrm{B}$ and $\mathrm{Al}$ possessed the most efficient transfer rate exceeding $50 \%$, while $\mathrm{N}, \mathrm{V}$ and $\mathrm{Ti}$ were transferred from the source to the $3 \mathrm{C}-\mathrm{SiC}$ epilayer at a rate of about $10 \%$. (Table 1 ).

As seen in Fig. 5c-d the two sources have different surface morphologies after the 3C$\mathrm{SiC}$ layer growth by sublimation which, in fact, resulted in thermal etching of the source surface and revealed various defects and grains which cause inhomogeneous sublimation. In case of the $\mathrm{SiC}: \mathrm{B}, \mathrm{N}$ source, the surface possesses a mosaic structure with well-defined grain boundaries. As shown in previous studies, the boron concentration between the grains of different polytypes can only slightly vary and no inter-diffusion of boron between grains occurs at typical growth temperatures used in sublimation epitaxy (35). Also, the sublimation rate of different grains can differ which can be attributed to the inclination angle of grains (36). The same applies to the $\mathrm{SiC}: \mathrm{V}, \mathrm{B}, \mathrm{Al}, \mathrm{Ti}$ source. However, due to the lower solubility limit of $\mathrm{V}\left(\sim 3 \times \mathrm{E} 17 \mathrm{~cm}^{-3}\right)$ in $\mathrm{SiC}$ compared to B $\left(\sim 2.5 \times \mathrm{E} 20 \mathrm{~cm}^{-3}\right), \mathrm{Al}(\sim 2 \times \mathrm{E} 21)$ and $\mathrm{N}\left(\sim 6 \times \mathrm{E} 20 \mathrm{~cm}^{-3}\right)$ there are areas in grains or at the grain boundaries with V-rich phases (confirmed by SIMS) which sublimate slower than $\mathrm{SiC}$ and create $3 \mathrm{D}$ structures on the source surface after the $3 \mathrm{C}-\mathrm{SiC}$ growth. 


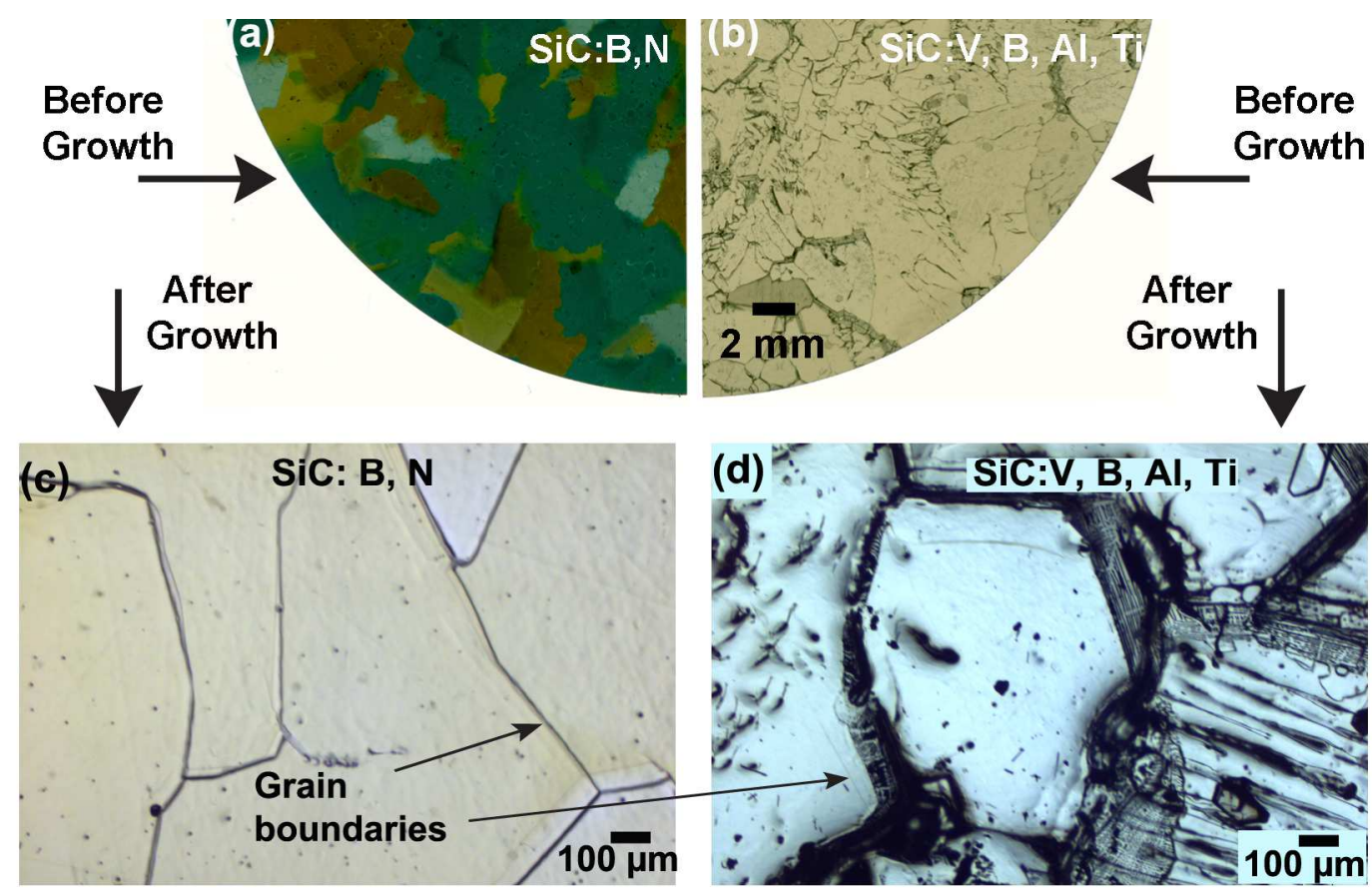

Figure 5. Optical micrograph of polycrystalline $\mathrm{SiC}$ source before homoepitaxial 3C-SiC growth: a) $\mathrm{SiC}: \mathrm{B}, \mathrm{N}$, b) SiC: V, B, Al, Ti and after the growth: c) $\mathrm{SiC}: \mathrm{B}, \mathrm{N}$, d) $\mathrm{SiC}: \mathrm{V}, \mathrm{B}, \mathrm{Al}$, Ti.

TABLE I. Impurities transfer rate

\begin{tabular}{cccccc}
\hline & $\mathbf{B}$ & $\mathbf{N}$ & $\mathbf{V}$ & Al & Ti \\
\hline Transfer rate (\%) & $\sim 60$ & $\sim 9$ & $\sim 10$ & $\sim 60$ & $\sim 7$
\end{tabular}

We observed that some structural defects like micrometer size polycrystalline inclusions can be formed in homoepitaxial layers of 3C-SiC using $\mathrm{SiC}: \mathrm{V}, \mathrm{B}, \mathrm{Al}, \mathrm{Ti}$ source. However, such defects were significantly reduced by lowering the growth temperature/growth rate $(<100 \mu \mathrm{m} / \mathrm{h})$, while the formation of polycrystalline defects in homoepitaxial 3C-SiC layers was not observed using $\mathrm{SiC}$ : B, N source at the growth rates up to $200 \mu \mathrm{m} / \mathrm{h}$.

Considering that $\mathrm{V}$ doping is commonly used in growth of hexagonal $\mathrm{SiC}$ boules to obtain high resistivity $\mathrm{SiC}$ wafers we did electrical measurements on $\mathrm{V}$ doped homoepitaxial 3C-SiC layers in the geometry shown in Fig. 6a. We obtained a resistivity of $9.9 \times \mathrm{E} 4 \Omega \mathrm{cm}$ at room temperature in intentionally $\mathrm{V}$ doped $3 \mathrm{C}-\mathrm{SiC}$. The material is $\mathrm{p}$ type. For comparison, we have performed resistivity measurements in a reference $3 \mathrm{C}$-SiC layer grown without $\mathrm{V}$ doping using pure $\mathrm{CVD} \mathrm{SiC}$ source. The resistivity of the reference $3 \mathrm{C}-\mathrm{SiC}$ sample was only $40 \Omega \mathrm{cm}$.

The resistivity in $\mathrm{V}$ doped sample was estimated from the series resistance of $25 \times \mathrm{E} 6 \Omega$ which was extrapolated from the I-V curve (Fig. 6b) measured on the Pt/3C-SiC Schottky diodes by linear fitting of the $\mathrm{dV} / \mathrm{d} \ln (\mathrm{I})$ vs I plot (Fig. 6c). Based on SIMS, in addition to $\mathrm{V}\left(\sim 3 \times \mathrm{E} 16 \mathrm{~cm}^{-3}\right)$ the homoepitaxial $3 \mathrm{C}$-SiC layer contains B (low $1 \times \mathrm{E} 17 \mathrm{~cm}^{-}$ $\left.{ }^{3}\right), \mathrm{Al}\left(\sim 3 \times \mathrm{E} 16 \mathrm{~cm}^{-3}\right), \mathrm{N}$ (below detection limit $\left.\sim 5 \times \mathrm{E} 17 \mathrm{~cm}^{-3}\right)$ and Ti $\left(\sim 2.5 \times \mathrm{E} 15 \mathrm{~cm}^{-3}\right)$. In addition, temperature dependent measurements from room temperature to $400 \mathrm{~K}$ indicate that a dominant acceptor level is located at around $212 \mathrm{meV}$ which can be assigned to aluminum doping (Fig. 6d). It is challenging to discuss in this case the role of $\mathrm{V}$ in the compensation leading to such resistivity value. Presumably, much higher resistivity values and a related compensation model could be obtained by using $\mathrm{V}$ doped $\mathrm{SiC}$ source with more favorable $\mathrm{V}$ concentration and less background doping. 
(a)

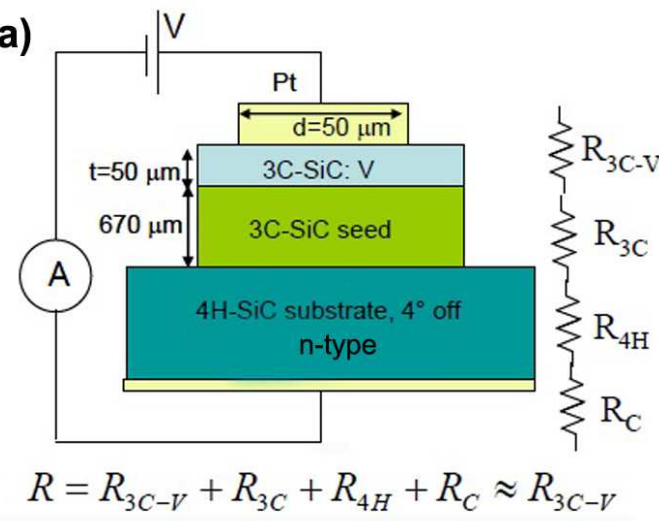

(c)

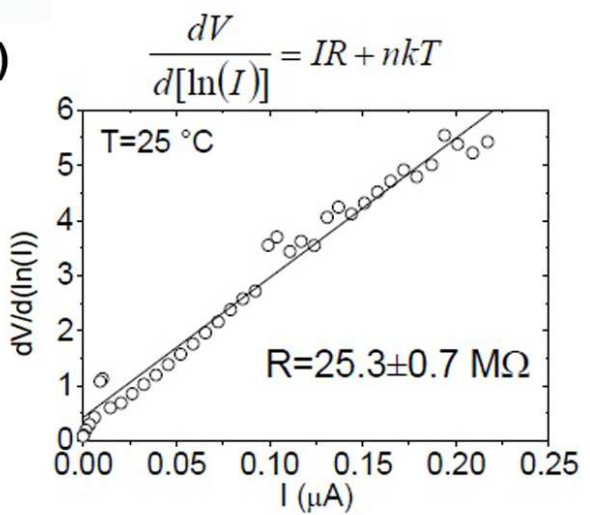

(b)

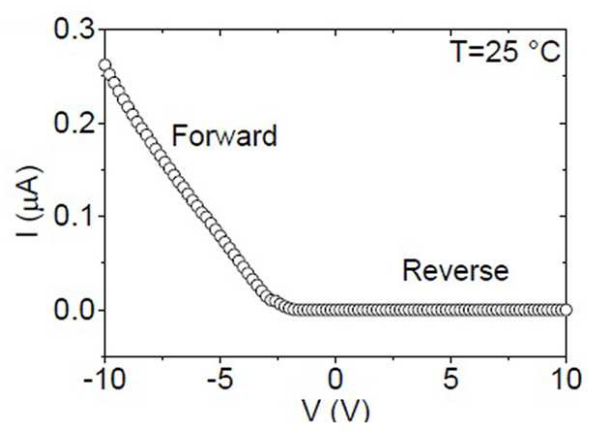

(d)



Figure 6. a) schematic drawing of Pt/3C-SiC Schottky diode, b) I-V curve of V doped 3C-SiC, c) fitting of $d V / d(\ln (I))$ and d) temperature dependent fitting of $\ln (\rho(\Omega \mathrm{cm}))$

We have performed optical measurements to obtain additional evidence about $\mathrm{V}$ incorporation. The low-temperature photoluminescence of the $\mathrm{V}$-doped 3C-SiC sample was investigated using a Bomem DA8 FTIR with a Northcoast Ge detector. The dominating emission in the near-infrared spectral region consists of a doublet, as expected for substitutional $\mathrm{V}$ defect, owing to the spin-orbit splitting of the ground state of the PL transition (37). The spectrum is displayed in Fig. 7, where the known V-related spectra of the hexagonal $4 \mathrm{H}-$ and $6 \mathrm{H}$-polytypes are also shown for comparison.

The doublet observed in $3 \mathrm{C}-\mathrm{SiC}: \mathrm{V}$ resembles the doublet associated with the cubic site in $4 \mathrm{H}-\mathrm{SiC}: \mathrm{V}$ and denoted $\mathrm{V}(\mathrm{k})$ in Fig. 7. This would be the expected appearance of $\mathrm{V}$ - related emission in $3 \mathrm{C}$-SiC, because the $3 \mathrm{C}-\mathrm{SiC}$ only possesses cubic lattice sites. For comparison, the hexagonal lattice sites in $4 \mathrm{H}-$ and $6 \mathrm{H}-\mathrm{SiC}$ display also measurable spinorbit of the excited state in the PL transition (denoted V(h) in both polytypes), which leads to appearance of four lines at somewhat elevated temperature when the higher counterpart in the spin-orbit split excited state also becomes populated. Note, however, that the two lines in $6 \mathrm{H}-\mathrm{SiC}$ associated with the two inequivalent cubic lattice sites do not appear as doublets, presumably due to negligible spin-orbit splitting of the ground state. Another property of the V-related spectra is the significant shift of the spectra as whole with increasing hexagonality between $4 \mathrm{H}-$ and $6 \mathrm{H}-\mathrm{SiC}$. This empirical observation leads one to anticipate the $\mathrm{V}$-related emission in $3 \mathrm{C}$-SiC to have the lowest energy, as observed experimentally, cf. Fig. 7. Thus, we tentatively associate the observed doublet (two lines at energies 828.6 and $829.8 \mathrm{meV}$ ) with vanadium in $3 \mathrm{C}-\mathrm{SiC}$. 


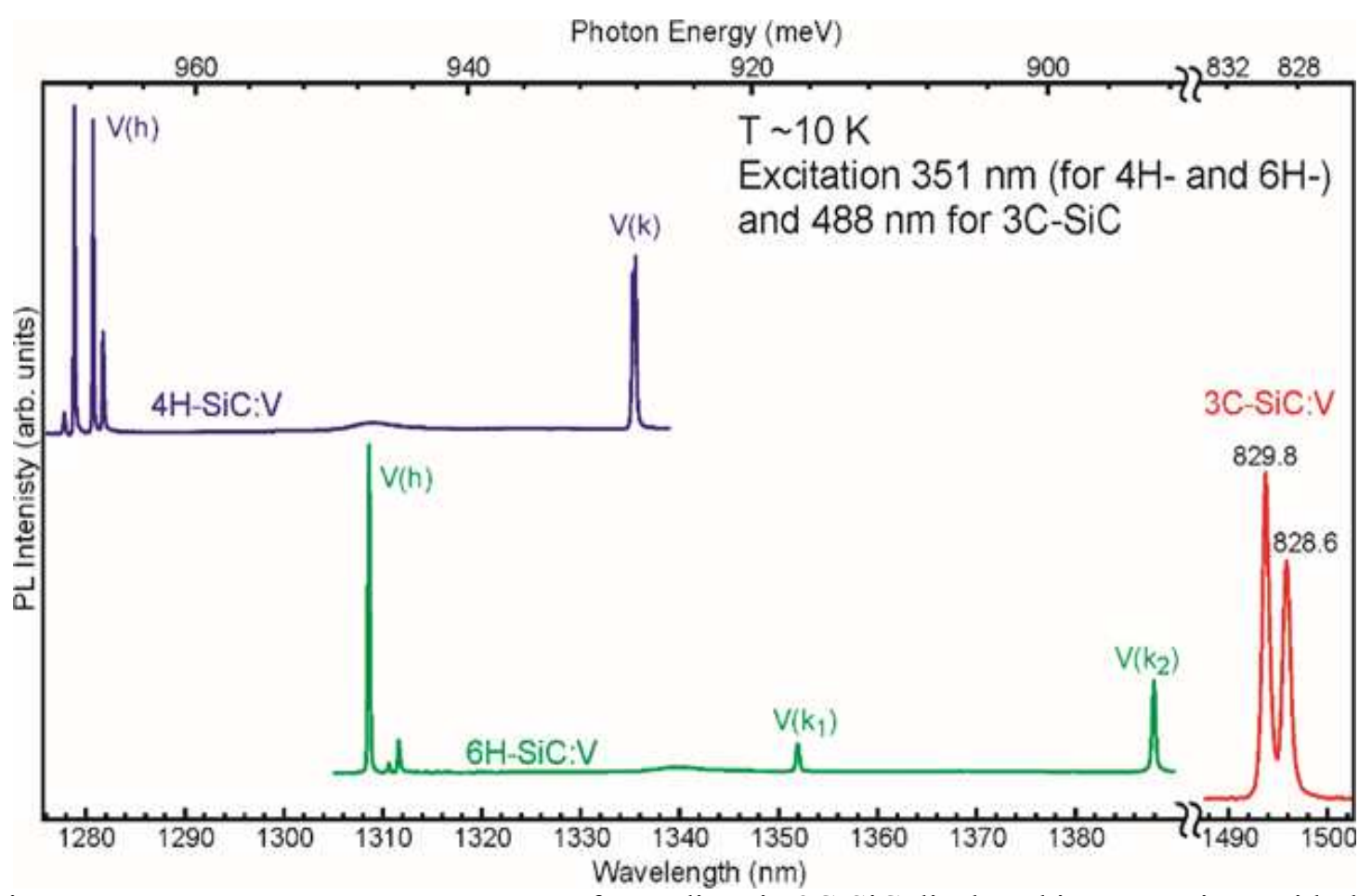

Figure 7. Low-temperature PL spectrum of vanadium in 3C-SiC displayed in comparison with the vanadium-related emission in $4 \mathrm{H}-$ and $6 \mathrm{H}-\mathrm{SiC}$. The peak positions of the two components of the doublet in $3 \mathrm{C}-\mathrm{SiC}$ are marked with the corresponding photon energies in meV. The peaks in the hexagonal $4 \mathrm{H}-$ and $6 \mathrm{H}$-polytypes are marked in accord with their assignment to vanadium at hexagonal $(\mathrm{V}(\mathrm{h}))$ or cubic $(\mathrm{V}(\mathrm{k}))$ inequivalent lattice sites. The $6 \mathrm{H}$-polytype has two inequivalent cubic lattice sites denoted $\mathrm{k}_{1}$ and $\mathrm{k}_{2}$. The doublet in $3 \mathrm{C}-\mathrm{SiC}$ resembles the one for the $\mathrm{V}(\mathrm{k})$ in $4 \mathrm{H}-$ $\mathrm{SiC}$ and is associated with spin-orbit splitting of the ground state of $\mathrm{V}$ in these two polytypes. Note the horizontal-axis brake.

\section{Conclusions}

We have presented a brief overview of the recent progress in growth of thick 3C-SiC layers by sublimation epitaxy at Linköping University. Considering the high crystalline quality and the significant reduction of defects, like DPBs, such layers can be used as seeds in bulk 3C-SiC growth or as substrates for homoepitaxial 3C-SiC growth by sublimation epitaxy or CVD techniques. We have verified that $3 \mathrm{C}-\mathrm{SiC}$ layers can be codoped from the source material and each impurity has a specific transfer rate. Vanadium, as a dopant of a primary interest for producing high resistivity material can be incorporated in the epitaxial layers without structure deterioration. It was revealed that more precise and selective co-doping needs a special source preparation to avoid high background doping. Concomitantly, growth of homoepitaxial 3C-SiC layers on 3C-SiC substrates produced by sublimation epitaxy can be thoroughly explored using other growth techniques.

\section{Acknowledgments}

This work was funded by the Swedish Research Council (621-2014-5825), ÅForsk foundation (16-576) and EU project CHALLENGE (project ID: 720827) 


\section{References}

1. G. R. Yazdi, Carbon N. Y. 57, 477-484 (2013).

2. P. Hens, Carbon N. Y. 80, 823-829 (2014).

3. Y. Zhu, Electron. Mater. Lett. 13, 142-146 (2017).

4. H. Uchida, Mater. Sci. Forum. 717-720, 1109-1112 (2012).

5. S. Castelletto, ACS Nano. 8, 7938-7947 (2014).

6. S. E. Saddow, Mater. Sci. Forum. 679-680, 824 (2011).

7. Q. Ma, Mater. Sci. Forum. 858, 291-294 (2016).

8. J. Sun, Mater. Sci. Forum. 858, 1028-1031 (2016).

9. A. L. Falk, Nat. Commun. 4, 1819 (2013).

10. D. J. Christle, Phys. Rev. X. 7, 21046 (2017).

11. F. Li, Mater. Sci. Forum. 858, 667-670 (2016).

12. R. Anzalone, Mater. Sci. Forum. 821-823, 773-776 (2015).

13. R. Anzalone, Adv. Sci. Technol. 54, 411-415 (2008).

14. J. F. Michaud, Mater. Sci. Forum. 806, 3-9 (2014).

15. M. Syvajarvi, J. Cryst. Growth. 197, 155-162 (1999).

16. V. Jokubavicius, Cryst. Growth Des. 15, 2940 (2015).

17. V. Jokubavicius, Cryst. Growth Des. 14, 6514-6520 (2014).

18. R. Vasiliauskas, - Cryst. Growth Des. 12, 197 (2012).

19. P. Hens, Mater. Lett. 67, 300-302 (2012).

20. Y. A. Vodakov, Phys. status solidi. 202, 177-200 (1997).

21. A. Fissel, Phys. Rep. 379, 149-255 (2003).

22. U. Starke, Phys. Rev. Lett. 82, 2107 (1999).

23. S. K. Lilov, Comput. Mater. Sci. 1, 363-368 (1993).

24. R. Yakimova, Mater. Sci. Forum. 711, 3 (2012).

25. R. Yakimova, Mater. Sci. Forum. 527, 283 (2006).

26. A. A. Lebedev, Semiconductors. 41, 263 (2007).

27. R. Vasiliauskas, J. Cryst. Growth. 324, 7-14 (2011).

28. T. Kimoto, J. Appl. Phys. 75, 850-859 (1994).

29. J. Eriksson, Appl. Phys. Lett. 95, 81907 (2009).

30. R. Vasiliauskas, Mater. Lett. 74, 203-205 (2012).

31. P. Wellmann, J. Cryst. Growth. 275, e555-e560 (2005).

32. R. R. Ciechonski, J. Electron. Mater. 32, 452-457 (2003).

33. M. Kaiser, IOP Conf. Ser. Mater. Sci. Eng. 56, 12001 (2014).

34. J. Camassel, Chem. Vap. Depos. 12, 549-556 (2006).

35. M. K. Linnarsson, Mater. Sci. Forum. 740-742, 397-400 (2013).

36. M. Kaiser, Mater. Sci. Forum. 740-742, 39-42 (2013).

37. K. Maier, Mater. Sci. Eng. B. 11, 27-30 (1992). 